\title{
Do wild titi monkeys show empathy?
}

\author{
A. Clyvia ${ }^{1}$, M. C. Kaizer $^{1}$, R. V. Santos ${ }^{1}$, R. J. Young ${ }^{1,2}$, and C. Cäsar ${ }^{1,3}$ \\ ${ }^{1}$ Conservation, Ecology and Animal Behaviour Group, Programa de Pós-Graduação em Zoologia, \\ Pontifícia Universidade Católica de Minas Gerais, Belo Horizonte, Brazil \\ ${ }^{2}$ University of Salford Manchester, School of Environment \& Life Sciences, Manchester, UK \\ ${ }^{3}$ Bicho do Mato Instituto de Pesquisa, Belo Horizonte, Brazil \\ Correspondence to: C. Cäsar (criscasar@gmail.com)
}

Received: 31 May 2014 - Revised: 3 October 2014 - Accepted: 7 October 2014 - Published: 28 October 2014

\begin{abstract}
We observed a putative case of empathy among wild black-fronted titi monkeys (Callicebus nigrifrons) from two different groups (D and R). In over 10 years of behavioural observations of five habituated groups of this species, only low levels of inter-group tolerance have been observed. However, on one day, we encountered the adult male from group D limping (poor hind limb motor coordination) as he travelled alone along the ground. Interestingly, we observed that members of group R did not express any agonistic behaviour towards this neighbouring male and apparently allowed this disabled individual to follow them in the forest for over $5 \mathrm{~h}$. They stayed low in the forest ( $<2 \mathrm{~m}$ above the ground) and $<10 \mathrm{~m}$ horizontally from the individual, and remained in visual contact with him. At the end of the day, this male from group D slept in the sleeping site of group R and was groomed by the adult female of group R. Such tolerance between members of different groups has never been previously observed in this species. Furthermore, group R exposed themselves to increased predation risk by staying close to the ground for protracted periods. The behaviour of group $\mathrm{R}$ could be interpreted by as a putative case of empathic responding in this species.
\end{abstract}

\section{Introduction}

Empathy has been defined as the relationship that occurs between the perception and action of the emotional state of an individual towards another being, and is considered essential for directional cooperation in achieving a shared goal and in some social interactions (perception-action model - PAM; Preston and de Waal, 2002; de Waal, 2008). More specifically, the PAM is a firm, hard-wired basis, in which higher cognitive levels of empathy (including sympathetic concern and perspective taking) can be built upon (de Waal, 2003, 2008).

While more complex, cognitive forms of empathy exist, any empathic process involves a level of personal distress and emotional contagion at its base, which is often difficult to analyze because there is variation in its definition and identification (Preston and de Waal, 2002). Despite the arguments against the presence of empathy in nonhuman animals (Silk, 2007), there are a growing number of scientific studies reporting behaviours which appear to be driven by empathy. Thus, empathy has been suggested in the context of contagious yawning (Campbell and de Waal, 2011; Demuru and Palagi, 2012), affiliative behaviours towards distressed individuals during post-conflict situations - like consolation (Romero et al., 2011; Clay and de Waal, 2013; Palagi et al., 2014), and modulation of pain sensitivity (Langford et al., 2006).

Studies suggest that empathic processes are observed in some species of birds (Watanabe and Ono, 1986; Seed et al., 2007; Wascher et al., 2008) and mammals (Connor and Norris, 1982; Langford et al., 2006; Bates et al., 2008), especially by apes (Povinelli et al., 1992; Silk et al., 2005; Schino and Marini, 2012; Tokuyama et al., 2012; Clay and de Waal, 2013). Although empathetic concern was previously thought to be confined to the great apes and animals with large neocortex, some new evidence suggests that simpler forms exist in other animal species. Bartal et al. (2011), for instance have shown pro-social behaviour in an experimental set-up in which free rats were sensitive to another rat's distress and 
acted intentionally to liberate a trapped conspecific, even in the absence of training or social reward.

Our study subject is one species of titi monkey, the blackfronted titi monkey (Callicebus nigrifrons), living in fragments of Atlantic Forest, in Southeast Brazil. The primates of the genus Callicebus (titi monkeys) are socially monogamous and live in small family groups from 2 to 7 individuals (Kinzey and Becker, 1983). They are characterized by a strong bond between the male and female of a pair, who spend a lot of time in contact, with their tails entwined and grooming each other (Mason, 1966, 1974; Anzenberger et al., 1986; Fernandez-Duque et al., 1997). Lactating mothers feed the infant in the first 8 to 12 weeks; however, the father is the main caregiver of the single offspring, accounting for about 80 to almost $100 \%$ of all infant carrying (Wright, 1984; Kinzey, 1981; Mendoza and Mason, 1986; Hoffmann et al., 1995). Dispersal from the natal group occurs between two to four years of age (Bossuyt, 2002) and there is no apparent pressure from other members of the group (Mayeaux et al., 2002; Bossuyt, 2002). Titi monkeys are highly territorial and pairs defend their territories by duetting and displaying other aggressive behaviours (e.g. piloerection, tail-lashing and chasing) to neighbouring pairs at their boundaries (Robinson, 1979, 1981; Kinzey and Becker, 1983; Anzenberger et al., 1986).

In this study we observed a potential case of empathy in wild titi monkeys and suggest some hypotheses to explain this behaviour. We also relate our report to other nonhuman primates to help enhance the progression of knowledge on wild primate cognitive abilities.

\section{Methods}

Our subjects were two groups of Callicebus nigrifrons, a species endemic to the Atlantic forest and classified as near threatened (Veiga et al., 2008), which live in the Private Nature Reserve Santuário do Caraça, in Minas Gerais, Brazil $\left(20^{\circ} 05^{\prime} 52^{\prime \prime} \mathrm{S} ; 43^{\circ} 29^{\prime} 16^{\prime \prime} \mathrm{W}\right)$. Individuals can be identified by natural visual marks and have been habituated to human observer presence since 2003.

The groups involved in this case are called D and R. Each group consisted of 3 adults ( $>30$ months old), being a breeding pair and a male offspring (see Table 1). The composition of group $\mathrm{R}$ is typical and the male offspring was in process of dispersion because it was spending almost all day far from its natal group looking for new territories and a breeding partner (Easley and Kinzey, 1986). The composition of group D is considered atypical because the current female has been present for $<2$ years and was not the male offspring's mother (i.e. a "new" female).

These groups were observed monthly and their activity patterns were registered using focal animal samples for $10 \mathrm{~min}$ with instantaneous recording of behaviour every $60 \mathrm{~s}$
(Martin and Bateson, 2007). On 28 August 2011 we observed group R from 8 a.m. to 5.41 p.m.

To conduct our research we had authorization from the owners of the private nature reserve. We were conformed to international standards of ethical treatment of animals although we did not perform any type of experiment in the field and animals had been habituated to human observers for more than 8 years.

\section{Results}

Between October 2010 and January 2012, we observed frequent resource (i.e. feeding) competition between the two study groups, $\mathrm{R}$ and $\mathrm{D}$, which shared overlapping homeranges. For example, on 5 July 2011, at 10.15 a.m., we observed a vocal dispute involving all individuals and the breeding male of group D (DE) intensively chasing the female from group $\mathrm{R}$ (RS) for $2 \mathrm{~min}$, followed by this female physically attacking this male.

On 27 August 2011, we observed that male DE spent an unusually prolonged amount of time on the ground (from 10.18 a.m. to 5 p.m.; Fig. 1a; see the Supplement), a forest substrate rarely used by titi monkeys (Kinzey, 1997), while members of his group remained up in the trees. At one point, he fed and foraged for nearly $12 \mathrm{~min}$ on the ground. The rest of the group was not close to the individual throughout the day. We observed that DE was having difficulty in travelling and observed that he followed the researcher's trail on the ground. At times he would lie down for $>4 \mathrm{~min}$, and when he tried to climb up a tree, he lost his balance and fell. Only at 5 p.m., the individual climbed up a tree, with obvious difficulty, and then immediately went to the sleeping site where his group was located.

The next day, 28 August 2011, we observed the neighbouring group (group R) when at 12.27 p.m. we observed that DE was alone on the ground and approached us. During the time he was on the ground, the individual foraged, fed and travelled (remaining close to the researchers). The proximity to the researchers may be related to individual safety since the presence of humans may inhibit the approach of nonhabituated predators (Isbell and Young, 1993). At 12.40 p.m., the individual climbed up a tree and stayed near group R, which surprisingly did not show agonistic behaviour or vocalizations that are normal during inter-group encounters (Cäsar et al., 2012a). At 2.02 p.m. the male returned to the ground and followed group $\mathrm{R}$, without feeding anymore. The individual crossed a dirt road at a minimum distance of $1 \mathrm{~m}$ from the researchers (Fig. 1a). We noticed that the individual had a physical/health problem because of his abnormal locomotion style. At 2.14 p.m., group R was composed only of the breeding pair, since its other adult male (RF) was in the process of dispersion. At 2.31 p.m., DE climbed up a tree but remained in a low stratum (approximately $2.5 \mathrm{~m}$ above the ground) close to group $\mathrm{R}$. We observed that group $\mathrm{R}$ began 
Table 1. Age-sex class composition of the groups of black-fronted titi monkeys in Private Nature Reserve Santuário do Caraça, Minas Gerais, Brazil.

\begin{tabular}{lccccc}
\hline Group & Individual & Sex class & Age class & Status & Approximate age on August 2011 (months) \\
\hline D & DE & M & A & BP & 120 \\
& DS & F & A & BP & 60 \\
& DG & M & A & OF $^{*}$ & 84 \\
R & RB & M & A & BP & 120 \\
& RS & F & A & BP & 120 \\
& RF & M & A & OF & 87 \\
\hline
\end{tabular}

Sex class: $\mathrm{M}=$ male, $\mathrm{F}=$ female. Age class: $\mathrm{A}=$ adult, $>30$ months (Cäsar et al., 2012a). Status: $\mathrm{BP}=$ breeding pair, $\mathrm{OF}=$ offspring. * Offspring of DE with another female (DI), which disappeared or died in November 2009.

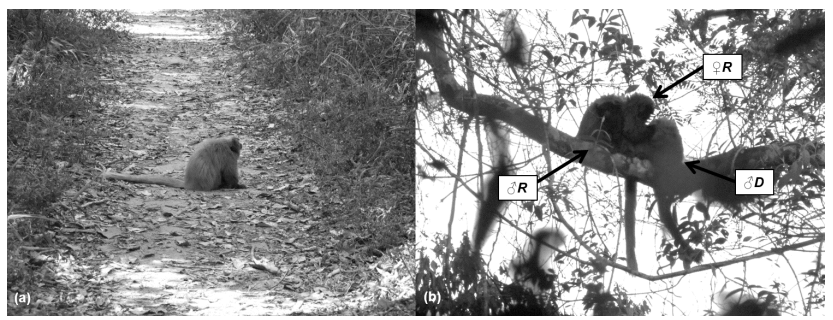

Figure 1. (a) Male black-fronted titi monkeys of group D resting on a dirt road at the study site; (b) at the sleeping site, couple $\mathrm{R}$ and male group $\mathrm{D}$, female of group $\mathrm{R}$ grooming the male of group $\mathrm{D}$ (Photos by M. C. Kaizer).

to travel more slowly and appeared to wait for the injured male to catch-up with them. Each time the male laid down on a branch, group R stopped and remained close to him. The female from group R-RS (i.e. the same female that attacked the male on 5 July) descended to a stratum closer to the male and began observing him. Differently from what is expected for the species, the female produced no vocalizations when descending to the lower stratum (Cäsar et al., 2012a).

At 5.01 p.m., RS selected a sleeping site, followed by her male. At 5.15 p.m., the limping male arrived at the same sleeping site, leant against the female and intertwined his tail with hers for $150 \mathrm{~s}$. She then groomed DE for $34 \mathrm{~s}$ (Fig. 1b) which was fully tolerated by her male partner (RB). Finally, the 3 individuals stopped interactions and remained inactive until sunset. At no point during the day were other members of group D seen near group R. From 29 August 2011 onwards, DE was never seen again and presumably died.

Although the difference was not significant ( $G$ test Williams: $G_{\text {adjusted }}=6.2840$; d.f. $=3 ; p=0.0986$ ), group R showed a tendency for less time feeding $(28 \%$ vs. $35 \%)$ and more time socializing (5\% vs. $0.4 \%)$ and travelling (14\% vs. $9 \%$ ) during the day of this event in comparison to the annual average of these behaviours. The amount of time spent resting was very similar between the two periods (53\% vs. $55 \%)$.

\section{Discussion}

In our study species, no behaviour akin to intergroup and/or intragroup empathy has been previously documented. It is worth mentioning that we have previously reported a case of adoption in our study groups (Cäsar and Young, 2008). However, the lack of information on how the infant was adopted (plus at least a couple of observed tentative kidnapping, Cäsar et al., unpublished data) suggests that the reported adoption was not necessarily an empathetic case. Thus, this is the first observed case of putative empathic responding within titi monkeys.

Social species, such as primates, need mechanisms that regulate the interactions between group members to facilitate group cohesion and emotional awareness, and is thought to play a key role in this (Parr et al., 2005). These mechanisms have been discussed using the social brain hypothesis, which suggests that primates with bigger neocortices are better able to interpret behavioural signals and can thus better react to the emotional state of the other (Dunbar, 1998). However, growing evidence has been shown that other mammals and birds show empathy-related responses in the absence of a large neocortex, suggesting that other mechanisms are involved in the ability to understand and respond to the affective state of a conspecific (Wascher et al., 2008; Bartal et al., 2011).

Within the primate lineage, sympathetic concern was first thought to be confined to the great apes, and only recently has been opened up to monkey species (Palagi et al., 2014). Some examples of compensatory and/or compassionate care among new world primates (Chapman and Chapman, 1987; Tirado Herrera and Heymann, 2004; Bezerra et al., 2014) could also be interpreted as empathetic behaviours. However, the circumstances described in these studies were based on interactions between groups members, which is different from the case reported here. Chapman and Chapman (1987), for instance, reported compensatory care for an injured juvenile spider monkey, by his mother long after weaning. Tirado Herrera and Heymann (2004) reported behavioural responses of moustached tamarins to an injured group member that helped to maintain contact with this individual. In contrast 
to previous work, the present study shows an empathetic response towards an individual of a different group.

Empathy is more likely to occur when there is social proximity and kinship between individuals as it is thought to originate from the mother-offspring bond (Preston and de Waal, 2002). But that does not mean that unrelated individuals do not have the perception of mental and/or emotional state of other individuals so long as they are familiar (O'Connell, 1995). Unfortunately, we do not have genetic kinship data for our study groups but it is likely that individuals are related as home-ranges overlapped by $>35 \%$ (Santos, 2012). This could indeed explain the emotional engagement between them. In relation to this, we previously observed a case of adoption among the groups involved in this study (Cäsar and Young, 2008). Nevertheless, even in the absence of kinship, empathy could have appeared because of familiarity due to overlapping home-ranges. Working with semifree bonobos (Pan paniscus), Clay and de Waal (2013) have found that partners sharing strong affiliative bonds were more likely to be sensitive to each other's distress, even in the absence of genetic ties. Besides, nearby bystanders were also more likely to contact victims than more distal ones.

An intriguing aspect of the event described here, however, is that group D's members were previously not observed displaying any kind of affiliative behaviour towards the male. One explanation for this could be that the adult offspring was actually competing sexually for the female against his father, which would explain why the latter was found limping and alone. Although a case of paternal dispersal has never been reported for this species, the presence of a new female unrelated to both father and offspring could stimulate the dispersal of any of these males. In fact, it is worth mention that although the new female has been apparently paired with the older male for almost two years, she has also been involved in sexual behaviours (e.g. inspections and copulas) with the adult male offspring (C. Cäsar, personal communication, 2009). The relationship between these two males is deduced from the length of time the offspring DG has been present in the group. DG was first seen with the adult male DE (and his previous female) when he was about 1 year old, and although he has tried to disperse several times, while the previous female was still in the group, he has kept returning to his putative family group.

Another interesting aspect of this case study is that the paired female from one group $(\mathrm{R})$ was observed displaying affiliative behaviour towards an adult male from a neighbouring group (D) - something we have never seen before and has not been reported in the scientific literature. Other unexpected reactions of the female suggest that she did so as an expression of empathic behaviour towards the male: staying in a lower stratum than usual (Kinzey, 1997), watching and accompanying the male. These behaviours may even have increased her risk of predation by terrestrial predators such as medium-to-large cats (ocelots, oncillas, jaguarondis, pumas) and tayras (Cäsar et al., 2012b), besides reducing foraging time. Additionally, affiliative behaviours, such as grooming and tail intertwining were not expected in this situation, as they have primarily a social function within groups (Moynihan, 1966; Mason, 1966, 1974; Anzenberger et al., 1986; Fernandez-Duque et al., 1997). During experimental conditions, grooming among unrelated individuals was not frequent, even after prolonged separation between individuals of a breeding pair (Fernandez-Duque et al., 1997). The peculiarity of what we observed is the fact that even though the group R male was on the same branch and in direct constant contact with the female, the female groomed the other male; this male-male tolerance was completely unexpected. If $\mathrm{DE}$ was to be dispersing to group $\mathrm{R}$, we would expect an aggressive response, at least from the male $\mathrm{RB}$, which did not happen, suggesting that DE was not considered a threat to the paired male. Assuming that males D and R are related, it could be also argued that they could stay together in a new group, as reported in one case by Bicca-Marques et al. (2002); however, based on previously observed behaviours (such as chasing and pilo-erection) we believe this possibility to be unlikely. Finally, the female could be also interested in some kind of injury the male may had. This kind of interest for others' injuries is very frequent, for instance, within wild bonobos of different age-sex individuals which approach injured animals and usually lick their wounds (Tokuyama et al., 2012). However, we did not notice any visible injury on the male; but this does not exclude the possibility that the female could have noticed something we were not able to see.

While it is difficult to ascertain the underlining mechanisms involved in this event, we believe these data support our hypothesis that wild titi monkeys can express behaviours that are homologous to empathy. Both the paired male and female showed an unusually high level of acceptance towards an injured adult male. Moreover, the female displayed affiliative behaviours (e.g grooming and tail entwining) which are mostly common between mated pairs (and their offsprings) and have not been previously seen between individuals of neighbouring groups. This event suggests that empathy may be less cognitively complex than previously assumed. The fact that rats and some monkey species (including titi monkeys) show empathic orientation to others in distress suggests that the mechanisms underlying this behaviour may follow a more general pattern within the mammalian lineage. More specific studies will be required to investigate this hypothesis in detail.

\section{The Supplement related to this article is available online at doi:10.5194/pb-1-23-2014-supplement.}


Author contributions. A. Clyvia, M. C. Kaizer and R. V. Santos have observed the event in the field. A. Clyvia prepared the manuscript with contributions from M. C. Kaizer, C. Cäsar and R. J. Young. We declare that we have no conflict of interest.

Acknowledgements. We would like to thank Zanna Clay and two anonymous referees for helpful comments on a previous draft. Thanks to the Priests Wilson and Donizete for allowing us to conduct this study and the service employees for their help. We thank Vandilson Faria for assistance in the field and all contributors to the long-term demographic monitoring project. A. Clyvia and M. C. Kaizer were supported by postgraduate studentships from Coordenação de Aperfeiçoamento de Pessoal de Nível Superior (CAPES) and R. V. Santos was supported by Fundação de Amparo à Pesquisa do Estado de Minas Gerais (FAPEMIG); C. Cäsar was supported by $\mathrm{PhD}$ and Post-doc scholarships from CAPES and FAPEMIG, R. J. Young received financial support from FAPEMIG and CNPq.

Edited by: U. Radespiel

Reviewed by: two anonymous referees

\section{References}

Anzenberger, G., Mendoza, S. P., and Mason, W. A.: Comparative studies of social behavior in Callicebus and Saimiri: behavioral and physiological responses of established pairs to unfamiliar pairs, Am. J. Primatol., 11, 37-51, 1986.

Bates, L. A., Lee, P. C., Njiraini, N., Poole, J. H., Sayialel, K., Sayialel, S., Moss, C. J., and Byrne, R. W.: Do elephants show empathy?, J. Consciousness Stud., 15, 204-225, 2008.

Bartal, I. B. A., Decety, J., and Mason, P.: Empathy and pro-social behavior in rats, Science, 334, 1427-1430, 2011.

Bezerra, B. M., Keasey, M. P., Schiel, N., and Souto, A. S.: Responses towards a dying adult group member in a wild New World monkey, Primates, 55, 185-188, 2014.

Bicca-Marques, J. C., Garber, P. A., and Azevedo-Lopes, M. A. O.: Evidence of three resident adult male group members in a species of monogamous primate, the red titi monkey (Callicebus cupreus), Mammalia, 66, 138-142, 2002.

Bossuyt, F.: Natal dispersal of titi monkeys (Callicebus moloch) at Cocha Cashu, Manu National Park, Peru, Am. J. Phys. Anthropol, 117, 35-59, doi:10.1002/ajpa.20010, 2002.

Campbell, M. W. and de Waal, F. B. M.: Ingroup-Outgroup bias in contagious yawning by chimpanzees supports link to empathy, Plos One, 6, e18283, doi:10.1371/journal.pone.0018283, 2011.

Cäsar, C. and Young, R. J.: A case of adoption in a wild group of black-fronted titi monkeys (Callicebus nigrifrons), Primates, 49, 146-148, 2008.

Cäsar, C., Byrne, R. W., Young, R. J., and Zuberbühler, K.: The alarm call system of wild black-fronted titi monkeys, Callicebus nigrifrons, Behav. Ecol. Sociobiol., 66, 653-667, 2012a.

Cäsar, C., Byrne, R. W., Hoppitt, W., Young, R. J., and Zuberbühler, K.: Evidence for semantic communication in titi monkey alarm calls, Anim. Behav., 84, 405-411, 2012b.

Chapman, C. A. and Chapman, L. J.: Social Responses to the traumatic injury of a juvenile spider monkey (Ateles geoffroyi), Primates, 28, 271-275, 1987.
Clay, Z. and de Waal, F. B. M.: Bonobos respond to distress in others: consolation across the age spectrum, Plos One, 8, e55206, doi:10.1371/journal.pone.0055206, 2013.

Connor, R. C. and Norris, K. S.: Are dolphins reciprocal altruists?, Am. Nat., 119, 358-72, 1982.

de Waal, F. B. M.: On the possibility of animal empathy, in: Feelings \& Emotions: The Amsterdam Symposium, edited by: Manstead, T., Frijda, N., and Fischer, A., Cambridge University Press, Cambridge, UK, 379-399, 2003.

de Waal, F. B. M.: Putting the altruism back into altruism: The evolution of Empathy, Annu. Rev. Psychol., 59, 279-300, 2008.

Demuru, E. and Palagi, E.: In bonobos yawn contagion is higher among kin and friends, Plos One, 7, e49613, doi:10.1371/journal.pone.0049613, 2012.

Dunbar, R. I. M.: The Social brain hypothesis, Evol. Antropol., 6, 178-190, 1998.

Easley, S. P. and Kinzey, W. G.: Territorial shift in the yellowhanded titi monkey (Callicebus torquatus), Am. J. Primatol., 11, 307-318, 1986.

Fernadez-Duque, E., Mason, W. A., and Mendoza, S. P.: Effects of duration of separation on responses to mates and strangers in the monogamous titi monkeys, Am. J. Primatol., 43, 225-237, 1997.

Hoffman, K. A., Mendoza, S. P., Hennessy, M. B., and Mason, W. A.: Responses of infant titi monkeys Callicebus moloch, to removal of one or both parents: evidence for paternal attachment, Dev. Psychobiol., 28, 399-407, 1995.

Isbell, L. A. and Young, T. P.: Human presence reduces predation in a free-ranging vervet monkey population in Kenya, Anim. Behav., 45, 1233-1235, 1993.

Kinzey, W. G.: The titi monkeys, genus Callicebus, in: Ecology and Behaviour of Neotropical Primates, edited by: Coimbra-Filho, A. F. and Mittermeier, R. A., Vol. 1, Academia Brasileira de Ciências, Rio de Janeiro, Brasil, 241-276, 1981.

Kinzey, W. G. (Ed.): Callicebus, in New World Primates - Ecology, Evolution and Behavior, Aldine de Gruyter, New York, 213-221, 1997.

Kinzey, W. G. and Becker, M.: Activity pattern of the masked titi monkey, Callicebus personatus, Primates, 24, 337-343, 1983.

Langford, D. J., Crager, S. E., Shehzad, Z., Smith, S. B., Sotocinal, S. G., Levenstadt, J. S., Chanda, M. L., Levitin, D. J., and Mogil, J. S.: Social modulation of pain as evidence for empathy in mice, Science, 312, 1967-1970, 2006.

Martin, P. and Bateson, P. (Eds.): Measuring behavior: an introductory guide, Cambridge University Press, Cambridge, 2007.

Mason, W. A.: Social organization of the South American monkey, Callicebus moloch, a preliminary report, Tulane Stud. Zool., 13, 23-28, 1966.

Mason, W. A.: Comparative studies of social behavior in Callicebus and Saimiri: Behavior of male-female pairs, Folia Primatol., 22, 1-8, 1974.

Mayeaux, D. J., Mason, W. A., and Mendoza, S. P.: Developmental changes in responsiveness to parents and unfamiliar adults in a monogamous monkey (Callicebus moloch), Am. J. Primatol., 58, 71-89, 2002.

Mendoza, S. P. and Mason, W. A.: Parental division of labor and differentiation of attachments in a monogamy primate (Callicebus moloch), Anim. Behav., 34, 1336-1347, 1986.

Moynihan, M.: Communication in the titi monkey, Callicebus, J. Zool. Lond., 150, 77-127, 1966. 
O'Connell, S. M.: Empathy in chimpanzees: Evidence for theory of mind?, Primates, 36, 397-410, 1995.

Palagi, E., Dall'Olio, S., Demuru, E., and Stanyon, R.: Exploring the evolutionary foundations of empathy: consolation in monkeys, Evol. Hum. Behav., 35, 341-349, 2014.

Parr, L. A., Waller, B. M., and Fugate, J.: Emotional communication in primates: Implications for neurobiology, Curr. Opin. Neurobiol., 15, 716-720, 2005.

Povinelli, D. J., Nelson, K. E., and Boysen, S. T.: Comprehension of role reversal in chimpanzee: evidence of empathy?, Anim. Behav., 43, 633-640, 1992.

Preston, S. D. and de Waal, F. B. M.: Empathy: Its ultimate and proximate bases, Behav. Brain Sci., 25, 1-72, 2002.

Robinson, J. G.: Vocal regulation of use of space of titi monkeys Callicebus moloch, Behav. Ecol. Sociobiol., 5, 1-15, 1979.

Robinson, J. G.: Vocal regulation of inter- and intragroup spacing during boundary encounters in the titi monkey, Callicebus moloch, Primates, 22, 161-172, 1981.

Romero, T., Castellanos, M. A., and de Waal, F. B. M.: Postconflict affiliation by chimpanzees with aggressors: othersoriented versus selfish political strategy, Plos One, 6, e22173, doi:10.1371/journal.pone.0022173, 2011.

Santos, R. V.: Área de vida e uso do espaço por Callicebu snigrifrons Spix, 1823 (Primates: Pitheciidae), M.S. Dissertation, Pontifícia Universidade Católica de Minas Gerais, 65 pp., 2012.

Seed, A. M., Clayton, N. S., and Emery, N. J.: Post conflict thirdparty affiliation in rooks, Corvus frugilegus, Curr. Biol., 17, 15258, 2007.

Schino, G. and Marini, C.: Self-protective function of postconflict bystander affiliation in mandrills, Plos One, 7, e38936, doi:10.1371/journal.pone.0038936, 2012.
Silk, J. B.: Empathy, sympathy, and prosocial preferences in primates, in: Oxford Handbook of Evolutionary Psychology, edited by: Barrett, L. and Dunbar, R. I. M., Oxford University Press, Oxford, 115-126, 2007.

Silk, J. B., Brosnan, S. F., Vonk, J., Henrich, J., Povinelli, D. J., Richardson, A. S., Lambeth, S. P., Mascaro, J., and Schapiro, S. J.: Chimpanzees are indifferent to the welfare of unrelated group members, Nature Letters, 437, 1357-1359, 2005.

Tirado Herrera, E. R. and Heymann, E. W.: Behavioural changes in response to an injured group member in a group of wild moustached tamarins (Saguinus mystax), Neotropical Primates, 12, 13-15, 2004.

Tokuyama, N., Emikey, B., Bafike, B., Isolumbo, B., Iyokango, B., Mulavwa, M. N., and Furuichi, T.: Bonobos apparently search for a lost member injured by a snare, Primates, 53, 215-219, 2012.

Veiga, L. M., Kierulff, C. M., de Oliveira, M. M., and Mendes, S. L.: Callicebus nigrifrons, in: IUCN Red List of Threatened Species, available at: www.iucnredlist.org (last access: 14 May 2014), 2008

Wascher, C. A. F., Scheiber, I. B. R., and Kotrschal, K.: Heart rate modulation in by standing geese watching social and non-social events, P. R. Soc. B, 275, 1653-1659, 2008.

Watanabe, S. and Ono, K.: An experimental analysis of "empathic" response: effects of pain reactions of pigeon upon other pigeon's operant behavior, Behav. Proc., 13, 269-77, 1986.

Wright, P. C.: Ecological correlates of monogamy in: Aotus and Callicebus, in: Primate Ecology and Conservation, edited by: Else, J. C. and Lee, P. C., Cambridge University Press, Cambridge, 159-167, 1984. 